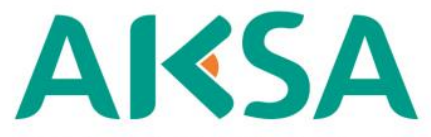

JURNAL DESAIN KOMUNIKASI VISUAL
AKSA JURNAL DESAIN KOMUNIKASI VISUAL

ISSN: 2615-1111 (online)

Available online at:

http://jurnalaksa.stsrdvisi.ac.id

\title{
Perancangan Brand dan Publisitas Padepokan Seni Topeng Asmorobangun untuk Meningkatkan Ekuitas Merek
}

\author{
Aditya Nirwana $^{1}$, Etsa Astridya Setiyati ${ }^{2}$ \\ ${ }^{1}$ Universitas Ma Chung \\ ${ }^{2}$ Universitas Ma Chung \\ Email: aditbraun@gmail.com
}

\section{ARTICLE INFO \\ Article history: \\ Received: 09 Mei 2018 \\ Revised: 23 Mei 2018 \\ Accepted: 24 Mei 2018}

\section{Keywords:}

Brand

Identity

Visual

Wayang

Topeng

\begin{abstract}
Wayang Topeng Malangan is a valuable cultural asset with various potentials for the development of the nation's character, but the many people in Malang are still unaware. Getting to understand the studio is the entrance for the people to understanding Wayang Topeng Malangan, one of which is Padepokan Seni Topeng Asmorobangun. The aim of this research is to obtain a visual marketing communication design in the form of Asmorobangun brand, that can increase brand equity, as well as marketing media that can become a medium of information for Malang city people to understanding Wayang Topeng Malangan.

With a customer-based marketing strategy (STP), and marketing mix $(4 P)$, the results is is the concept of design in the form of 'millenial', progressive, democratic, popular, which in itself offers value in a more progressive form. With visualizations communicating those positions, it is expected to foster brand equity in the target market of young people (men and women) at 18-25 years old, attend high school or college, be educated, familiar with technology, internet, and popular culture. Visualization of the concept, obtained brand identity such as logo, corporate color, typography, photography, illustrations, and supporting elements, and all of that implemented at ; 1) Poster; 2) Roll Banner; 3) Stationery; 4) Social media advertising; 5) Business Cards; 6) Corporate Identity System (CIS); 2) Site; and 3) Photo Books.
\end{abstract}

\section{PENDAHULUAN}

Wayang Topeng merupakan salah satu ragam wayang yang ada di Indonesia. Wayang secara keilmuan diakui sebagai Seni Pewayangan dan Seni Pedalangan, di mana dalang mendapatkan posisi yang cukup sentral dalam kesenian ini. Di tengah-tengah masyarakat salah satu ragam wayang yang paling populer adalah wayang kulit purwa, yang menceritakan kisah Mahabarata atau Ramayana. Holt (2000:156) dalam Art in Indonesia: Continuities and Changes, mengungkapkan wayang dalam arti yang sempit dan arti yang paling luas. Dalam artiannya yang 
paling sempit, kata wayang (secara harfiah berarti 'bayangan') menunjuk kepada boneka bertangkai dari kulit yang dipahat pipih dari wayang kulit. Bentuknya distilisasi dari boneka Jawa, seperti sebuah bayangan bentuk manusia Jawa yang alami. Adapun dalam artinya yang paling luas, kata wayang berarti sebuah pertunjukan dramatik, sebuah drama, sebuah tontonan, apakah itu aktornya boneka, atau manusia. Berdasarkan cerita yang dipertunjukkan, wayang topeng menyajikan repertoar dari cerita-cerita yang didasarkan pada legenda-legenda Panji, maka wayang topeng disini termasuk dalam wayang gedhog, namun dalam pertunjukkannya tidak menggunakan boneka-boneka wayang sebagai medium penyampai pesan, melainkan aktor manusia yang mengenakan topeng. Wayang topeng adalah sebuah pertunjukan pantomim-tari oleh aktor-aktor bertopeng, yang didalamnya alur diceritakan oleh seorang dalang, dan yang diutarakan adalah lakon-lakon yang didasarkan pada cerita-cerita Panji (Holt, 1967:65).

Wayang topeng merupakan kesenian rakyat dan memiliki posisi yang cukup strategis dalam pembentukan karakter masyarakat. Terkait dengan ini, Hidajat (2014) mengemukakan bahwa Wayang Topeng Malangan merupakan transmisi nilai-nilai lokal yang mengikat hubungan sosial antar individu dalam bermasyarakat (tindakan sosial), berdasarkan berbagai potensi berkesenian dalam dinamika kebudayaan masyarakat di Malang. Wayang Topeng Malangan merupakan proses pelembagaan komunikasi simbolik yang membentuk kesadaran baru masyarakat akan pengalaman hidup. Disamping itu, Wayang Topeng Melangan merupakan potensi yang membuat masyarakat mengubah persepsinya, dari pemahaman mitologis ke realitas. Perkembangan zaman menempatkan pola seni pertunjukan Wayang Topeng yang mampu mengkonstruksi sikap dan tata nilai dalam memahami realitas sosial, termasuk dalam memandang dunia yang memiliki dinamika di berbagai segmen kehidupan.

Peran kesenian Wayang Topeng Malangan yang strategis dan cukup menemukan urgensinya di masa kini, namun menjadi cukup ironis ketika menghadapi kenyataan bahwa 50\% remaja di kota Malang tidak mengenal Wayang Topeng Malangan (Melany, 2014). Lebih lanjut Melany (2014) mengemukakan bahwa dari 50\% remaja kota Malang yang tidak mengenal Wayang Topeng Malangan, 20\% remaja menganggap Wayang Topeng Malangan sudah "kuno”, $30 \%$ tidak memiliki akses untuk mengenal Wayang Topeng Malangan, dan 50\% lainnya menyatakan tidak memiliki informasi sama sekali mengenai Wayang Topeng Malangan. Kelestarian, pertumbuhan dan juga perkembangan Wayang Topeng Malangan tidak lepas dari peran serta pegiat-pegiat budaya tradisi, baik dalam bentuk kelompok seni ataupun padepokan. Setidaknya hal diatas menunjukkan bahwa padepokan-padepokan atau pegiat kesenian Wayang 
Topeng Malangan belum memiliki ekuitas merek bahkan di mata masyarakat kota Malang sekalipun.

Padepokan Asmorobangun merupakan salah satu padepokan pegiat kesenian Wayang Topeng Malangan, yang jika mengacu kepada kesenjangan antara pentingnya Wayang Topeng Malangan dengan realitas yang ada, maka perlu dipertimbangkan perancangan brand berikut ekuitas mereknya. Hal ini juga sejalan dengan kajian yang dilakukan oleh Khoirul, dkk (2013) yang menghasilkan 13 strategi pengembangan industri Topeng Malangan, dimana salah satunya adalah membangun strategi pemasaran yang baik, termasuk dengan memanfaatkan teknologi informasi.

Secara umum tujuan dari perancangan ini adalah memperoleh rancangan komunikasi visual pemasaran berupa brand padepokan Asmorobangun yang mampu meningkatkan ekuitas merek, serta media pemasaran sebagai implementasi dari brand yang berfungsi sebagai media informasi bagi masyarakat kota Malang dalam memahami Wayang Topeng Malangan. Hal ini dapat diwujudkan dalam bentuk konsep perancangan dan juga visualisasi desain, antara lain: 1) Memperoleh konsep perancangan brand dan publisitas padepokan Asmorobangun yang mampu meningkatkan ekuitas merek; dan 2) Memperoleh visualisasi komunikasi visual brand dan publisitas padepokan Asmorobangun yang artistik, dan mampu meningkatkan ekuitas merek, serta sebagai media informasi bagi masyarakat kota Malang dalam memahami Wayang Topeng Malangan.

Dalam penelitian ini, akan dilakukan perancangan terhadap brand padepokan Asmorobangun, website sebagai implementasi dari konsep brand, dan juga merchandise berupa photobook yang merupakan publisitas. Website dan photobook memuat beragam informasi yang dapat diakses oleh target konsumen sebagai sarana pembentuk kesadaran merek (brand awareness) yang merupakan bentuk pengetahuan akan merek disamping citra merek (brand image). Adapun publisitas merupakan salah satu elemen komunikasi pemasaran (Shimp, 2000:47). Penelitian perancangan ini dikonstruksi oleh landasan pemikiran bahwa brand equity dibangun dalam dua bentuk pengetahuan akan merek: 1) Kesadaran akan merek (brand awareness) dengan merancang publisitas (website dan photobook); dan 2) Citra merek (brand image) dengan merancang brand beserta atribut/ikon merek.

Brand atau dapat disebut juga sebagai merek merupakan nama, istilah, tanda, simbol, atau rancangan, atau kombinasi dari semuanya, yang dimaksudkan untuk mengidentifikasi barang atau jasa penjual atau kelompok penjual dan untuk mendiferensiasikannya dari barang atau jasa pesaing (Kottler \& Keller, 2007:332). Brand equity atau ekuitas merek adalah asosiasi 
positif dari merek di dalam benak konsumen yang dibuat, dan dibina oleh perusahaan/organisasi (O’Guinn, dkk, 2006:24). Shimp mendefinisikan ekuitas merek sebagai pengenalan konsumen atas merek tersebut dan menyimpannya dalam memori mereka beserta asosiasi merek yang mendukung, kuat, dan unik. Merek dalam perspektif konsumen terdiri atas 2 bentuk pengetahuan yakni: 1) Kesadaran merek (brand awareness), dan 2) citra merek (brand image) (2000:10-14).

Penelitian perancangan ini, dapat dipandang sebagai upaya peningkatan ekuitas merek melalui bentuk pengetahuan citra merek, melalui perancangan atribut yang tidak berhubungan langsung dengan produk berupa 1) Logo dan atribut merek (GSM Logo); 2) Website; dan 3) Photobook sebagai publisitas. Shimp (2000:14) juga mengungkapkan bahwa secara umum, usaha untuk meningkatkan ekuitas suatu merek dilakukan melalui pilihan yang positif atas identitas merek, yaitu pemilihan nama merek atau logo yang baik. Dalam menyusun konsep merek tersebut digunakan Customer-driven marketing strategy berupa strategi STP (Segmenting, Targeting, dan Positioning) dan marketing mix yang lebih berfokus pada product dan promotion.

Marketing mix merupakan konsep mayor dalam strategi pemasaran modern, yang dilakukan setelah melakukan STP strategy. Marketing mix merupakan seperangkat alat pemasaran taktis, dan mudah untuk dikontrol, untuk memproduksi respon yang diinginkan terhadap target market (Kotler \& Armstrong, 2008:48). Marketing mix adalah strategi mengombinasikan kegiatan-kegiatan marketing, agar tercipta kombinasi maksimal sehingga memunculkan hasil yang paling memuaskan (Alma, 2005:205). Bauran pemasaran mengandung beberapa hal yang dapat dilakukan oleh perusahaan untuk mempengaruhi permintaan produk di pasar. Bauran pemasaran ini dikenal sebagai 4P, yang terdiri dari 1) Product; 2) Price; 3) Place;

\section{4) Promotion.}

\section{METODE}

Penelitian yang akan dilaksanakan merupakan penelitian terapan atau dapat disebut sebagai penelitian perancangan, dimana hasil dari analisis data dipergunakan sebagai landasan dalam melakukan sintesis konsep perancangan. Adapun data yang terkumpul bersifat kualitatif, sehingga secara metodologis, penelitian perancangan ini merupakan penelitian kualitatif. Dalam penelitian perancangan ini terdapat tiga jenis kategori data, yaitu: 1) Data perusahaan berupa uraian mengenai sejarah padepokan Asmorobangun, profil, deskripsi organisasi, dan lain sebagainya; 2) Data produk, yakni data yang berkaitan dengan produk seni tradisi yang diproduksi oleh padepokan Asmorobangun beserta jasa yang ditawarkan; dan 3) Data pasar yang 
terdiri dari data mengenai kompetitor, target konsumen, dan lain sebagainya. Adapun tiga jenis kategori data tersebut diperoleh dengan teknik wawancara, dan observasi.

Metode analisis data yang dipergunakan dalam penelitian perancangan ini adalah metode perbandingan tetap. Secara umum proses analisis datanya mencakup: 1) Reduksi data; 2) Kategorisasi data; 3) Sintesisasi, dan diakhiri dengan 4) Menyusun hipotesis kerja (Moleong, 2014:288). Tahap selanjutnya adalah melakukan sintesisasi yakni mencari kaitan antara satu kategori dengan kategori lainnya. Tahap terakhir dari proses analisis data adalah menyusun hipotesis kerja berupa konsep perancangan, yang merupakan hasil/kesimpulan dari analisis data, Customer-driven marketing strategy (STP), dan juga marketing mix (4P). Konsep perancangan disebut juga sebagai konsep desain, berwujud konsep tertulis ataupun verbal. Konsep perancangan komunikasi visual ini didalamnya terdiri dari: 1) Perencanaan media (media plan);

2) Perencanaan kreatif (creative plan), dan 3) Perencanaan tata desain (design plan) (Sanyoto, 2006:61-62).

\section{PEMBAHASAN}

\subsection{Identifikasi dan Analisis Data}

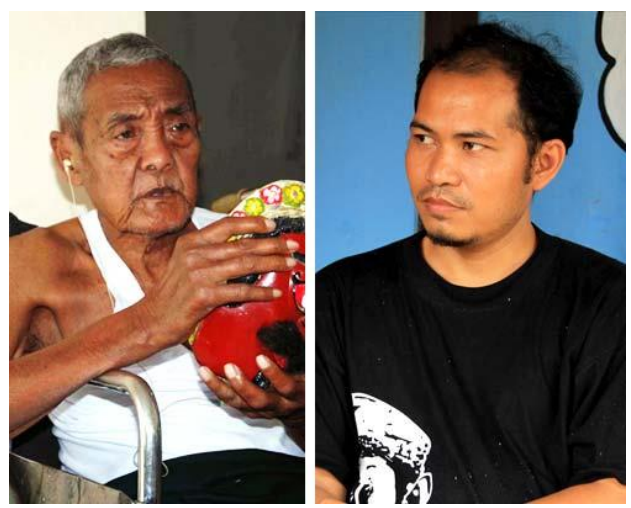

Gambar 1. Ki Karimoen, sang maestro Topeng (kiri), dan Tri Handoyo, cucu sekaligus murid Ki Karimoen yang saat ini memimpin Padepokan Asmorobangun.

(Sumber: dokumentasi penulis)

Melalui wawancara dan observasi didapatkan data produk dan jasa dari padepokan Asmorobangun. Padepokan Asmorobangun berdiri pada tahun 1982, diresmikan oleh Edi Slamet, Bupati Kabupaten Malang pada saat itu. Namun sebenarnya padepokan ini sudah berdiri sejak tahun 1900-an, dan sudah dikelola oleh 5 generasi. Generasi awal pendiri padepokan ini adalah mbah Serun, dan mbah Taslan, sebagai generasi pertama dan kedua. Saat itu padepokan ini bernama Pandawa Lima yang mementaskan repertoar sebagaimana Wayang Purwa, yakni 
epos Ramayana dan Mahabarata. Hingga pada generasi ketiga, yakni mbah Karimoen (Ki Karimoen) pada tahun 1982 tersebut diputuskan untuk mementaskan roman Panji, dan padepokan berganti nama menjadi Asmorobangun. Hingga pada pada generasi keempat yakni Pak Taslan, dan generasi kelima padepokan ini dipimpin oleh Tri Handoyo, lalu istilah 'padepokan' diubah menjadi 'Padepokan Seni Topeng' (Padepokan Seni Topeng Asmorobangun).

Produk dari padepokan Asmorobangun adalah kerajinan topeng. Kerajinan topeng ini pada dasarnya merupakan topeng yang dipergunakan sebagai properti tari atau pertunjukan Wayang Topeng Malangan, namun saat ini telah mengalami perubahan fungsi, disamping sebagai properti pertunjukan, topeng juga digunakan sebagai elemen estetik interior, souvenir, dan juga menjadi benda yang diyakini memiliki kekuatan supranatural. Pada jenis yang pertama, yakni topeng yang digunakan sebagai properti pertunjukan memiliki kualitas yang relatif sama (baik secara primer maupun sekunder) dengan topeng yang dipergunakan sebagai elemen estetik interior. Sehingga, keduanya dapat dianggap dalam kategori yang sama. Konsumen topeng pada jenis ini rata-rata adalah orang dewasa, baik itu masyarakat kota Malang sendiri, wisatawan luar kota, dan juga wisatawan luar negeri. Namun dua yang terakhir cukup mendominasi akhir-akhir ini, dan mulai banyak konsumen yang berasal dari kaum muda (mahasiswa).

Kedua, topeng yang berfungsi sebagai souvenir, yang tidak lain adalah gantungan kunci dan cindera mata (seringkali disebut sebagai 'vandel', semacam benda seni yang diberikan kepada orang sebagai bentuk apresiasi, atau dari segi fungsi, perannya mirip seperti trophy). Pada jenis ini, topeng telah mengalami reduksi besar-besaran, baik dari segi kualitas primer (ukuran), ataupun kualitas sekunder (struktur). Bentuknya yang kecil tidak memungkinkan untuk difungsikan sebagai properti pertunjukan, sehingga tidak dapat dikatakan sebagai 'topeng' dalam arti yang sebenarnya. Dalam bentuk gantungan kunci, jelas 'topeng' ini menjadi lebih murah. Konsumen pada jenis ini, kebanyakan berasal dari kalangan yang berada pada tahap awal pengenalan terhadap Topeng Malangan, atau orang-orang yang sebatas menggunakan Topeng Malangan sebagai simbol citraan belaka.
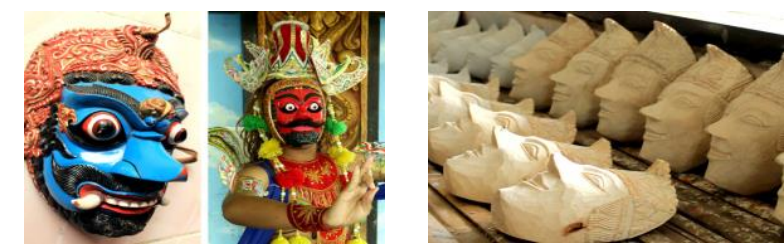

Gambar 2. Topeng pada kategori pertama (kiri) dan ragam karakternya sesaat sebelum diwarnai (kanan), dipergunakan sebagai properti pertunjukan Wayang Topeng Malangan atau elemen estetik interior.

(Sumber: dokumentasi penulis) 

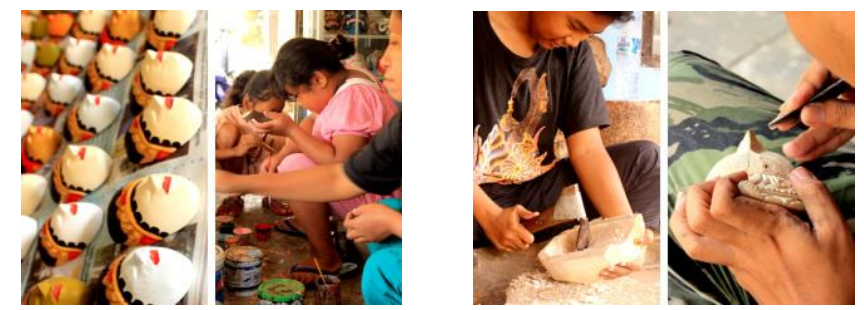

Gambar 3. 'Topeng' dalam bentuk gantungan kunci sebagai souvenir, beserta proses pembuatannya.

(Sumber: dokumentasi penulis)

Pada kategori yang ketiga, yakni topeng dengan fungsi 'khusus', yang diyakini memiliki 'manfaat' supranatural, dapat diidentifikasi kualitas sekunder yang lebih kompleks, meskipun secara kualitas primer tidak berbeda jauh dengan topeng yang dipergunakan sebagai properti pertunjukan dan elemen estetik interior. Topeng dengan fungsi khusus ini sebagian besar tidak diberi warna, sehingga nampak tekstur nyata material kayu. Konsumen produk topeng kategori ketiga ini tentunya lebih sedikit daripada konsumen jenis topeng yang pertama dan kedua, dan rata-rata terdiri dari konsumen usia dewasa dan usia lanjut, yang kebanyakan diantaranya pengamal ajaran spiritual Jawa, atau penghayat budaya tradisi Jawa.

Di samping menghasilkan produk, Padepokan Asmorobangun melaksanakan pertunjukan Wayang Topeng Malangan, dan tentunya ini merupakan 'jasa' yang paling utama dari padepokan ini. Pertunjukan Wayang Topeng Malangan dilaksanakan melalui beberapa jalan. Pertama, Padepokan diundang untuk melakukan pementasan di luar desa Kedungmonggo oleh orang-orang yang memiliki hajat, namun sebagaimana wayang kulit, hal ini sudah jarang sekali. Kedua, Padepokan Asmorobangun diundang untuk melakukan pementasan dalam perhelatanperhelatan yang diselenggarakan oleh pemerintah atau lembaga/institusi swasta. Bentuk yang kedua ini yang paling sering dilakukan. Ketiga, pementasan Wayang Topeng Malangan dilakukan secara rutin setiap bulan sekali dalam program Gebyak Senin Legian. Gebyak Senin Legian ini dilakukan di Pendopo Padepokan Asmorobangun setiap Senin Legi (Minggu malam, dalam sistem penanggalan Jawa, Minggu malam, di atas pukul 18.00 sudah masuk hari berikutnya), dan untuk menyaksikannya tidak diperlukan biaya, dan sangat terbuka untuk umum.

Di samping produk topeng dan jasa seni pertunjukan, Padepokan Asmorobangun juga menyelenggarakan pendidikan seni secara non-formal. Pertama, yakni latihan tari bersama yang diselenggarakan setiap Minggu pagi (08.00-10.00 WIB) yang diikuti oleh peserta dari usia anakanak hingga remaja akhir. Latihan bersama hari Minggu pagi ini sama sekali tidak dipungut biaya, data rata-rata diikuti oleh 10-20 orang peserta. Kedua, latihan tari secara intensif dalam bentuk kursus pada hari Sabtu pagi (08.00-10.00 WIB), dengan materi yang lebih terstruktur dan 
jumlah peserta yang lebih sedikit. Ketiga, pembelajaran cipta topeng yang juga dalam bentuk kursus.

Kalangan budayawan dan seniman tradisi di kota Malang, mengakui secara langsung mengenai keunggulan padepokan Asmorobangun. Sunari (62), budayawan dan seniman Topeng Malangan senior kota Malang, yang cukup lama mendampingi Tri Handoyo dalam mengembangkan padepokan Asmorobangun, mengakui bahwa topeng buatan padepokan Asmorobangun adalah yang terbaik, baik dari segi kualitas primer maupun sekunder di kota Malang. Di samping itu, topeng buatan padepokan Asmorobangun telah menjadi ciri khas suatu 'mazhab' dalam Topeng Malangan, yakni Topeng Kedungmonggo (gaya Kedungmonggo).

\subsubsection{Segmentasi, Targeting, dan Positioning}

Segmentasi dilakukan dengan mengamati ciri-ciri konsumen, seperti ciri-ciri geografis, demografis, dan psikografis. Dalam penelitian perancangan ini, dipergunakan pendekatan segmentasi benefit, dimana sasaran segmen dibedakan menjadi beragam paket benefit (manfaat) yang berbeda, yang diinginkan oleh konsumen dari produk kompetitor dan merek (O'Guinn, dkk., 2009:208). Berangkat dari hasil analisis data berupa asumsi bahwa segmen anak muda cukup memiliki peran yang strategis bagi kelestarian, kesinambungan, dan perkembangan Topeng Malangan baik hari ini maupun di masa depan, di tengah-tengah segmen dewasa-tua yang sudah mulai mengalami kejenuhan, maka dapat dirumuskan segmentasi sebagai berikut.

a. Segmentasi Geografis

Strategi pemasaran di dalam negeri (Indonesia), Provinsi Jawa Timur, khususnya Kabupaten dan Kota Malang.

b. Segmentasi Demografis

Usia muda (Sekolah Menengah Atas hingga Perguruan Tinggi) sebagai target pasar utama, yakni baik laki-laki maupun perempuan pada rentang usia 18-25 tahun.

c. Segmentasi Psikografis

Segmentasi psikografis dalam perancangan ini adalah kalangan muda yang akrab dengan teknologi, internet, dan budaya populer (generasi milenial), suka bergaul, memiliki banyak teman dan jaringan, suka berpetualang, dan tentunya mulai mengenal atau mulai menaruh perhatian pada seni tradisi.

\section{d. Segmentasi Behavioristik}

Perilaku segmen pasar yang menjadi sasaran di sini yakni pengguna langsung, yakni kalangan muda yang menikmati seni pertunjukan, membeli topeng, dan menggunakan jasa Padepokan Asmorobangun. 
Dari segmentasi yang telah dilakukan maka dapat diidentifikasi pasar sasaran (targeting), yakni anak muda (baik laki-laki maupun perempuan) pada usia 18-25 tahun, bersekolah SMA atau kuliah, terdidik, akrab dengan teknologi, internet, dan budaya populer (generasi milenial), suka bergaul, memiliki banyak teman dan jaringan, suka berpetualang, dan tentunya mulai mengenal atau mulai menaruh perhatian pada seni tradisi, yang merupakan pengguna langsung produk dan jasa Padepokan Asmorobangun. Adapun penetapan posisi atau positioning adalah tindakan merancang tawaran dan citra perusahaan sehingga menempati posisi yang khas (dibandingkan para pesaing) di dalam benak pelanggan sasaran (Kottler \& Keller, 2006:374375). Dalam perancangan ini, Padepokan Asmorobangun dihadirkan dalam citra 'milenial', yang progresif (berkemajuan), demokratis, populer, yang dengan sendirinya menawarkan nilai-nilai kebijaksanaan lokal dalam bentuk yang lebih progresif.

\subsubsection{Analisis Marketing Mix}

Marketing Mix atau Bauran pemasaran mengandung beberapa hal yang dapat dilakukan oleh perusahaan untuk mempengaruhi permintaan produk di pasar. Bauran pemasaran ini dikenal sebagai 4P, yang terdiri dari 1) Product; 2) Price; 3) Place; 4) Promotion. Dalam perancangan ini akan dilakukan perancangan website dan juga corporate identity system untuk membentuk kesadaran merek (brand awareness) target pasar, serta perancangan brand beserta atribut untuk membentuk citra merek (brand image) Padepokan Asmorobangun, atau sebagai medium untuk mengomunikasikan positioning kepada target pasar. Dalam konteks 4P, maka perancangan ini berfokus pada product dan promotion. Pada product, akan dilakukan perancangan pada aspek brand name, design, dan packaging. Sedangkan pada promotion, akan dilakukan perancangan pada aspek publicity.

\subsection{Sintesis Konsep}

Tahap selanjutnya adalah melakukan sintesisasi, yakni mencari kaitan antara satu kategori dengan kategori lainnya. Berlandaskan hasil/kesimpulan dari analisis data, Customerdriven marketing strategy (STP), dan juga marketing mix (4P), maka didapat sebuah konsep perancangan yakni merancang brand Padepokan Asmorobangun dalam bentuk atribut merek, berupa logo (lettermark, picturemark, typography, color), layout, ilustrasi, fotografi, poster, publikasi media sosial, bussiness card, dan juga stationery, yang kesemuanya terangkum dalam Corporate Identity System. Adapun dalam aspek publisitas, akan dirancang sebuah website dengan visualisasi yang konsisten dengan atribut merek yang sudah dirancang. Website 
dirancang dengan tujuan untuk mendekatkan padepokan dengan segmen anak muda, yang oleh karena itu website dirancang dengan interface yang liquid (mobile friendly).

Visualisasi dari atribut merk dan publisitas yang dirancang akan dihadirkan dalam citra 'milenial', yang progresif (berkemajuan), demokratis, populer, yang dengan sendirinya menawarkan nilai-nilai kebijaksanaan lokal dalam bentuk yang lebih progresif. Dengan visualisasi yang mengomunikasikan positioning tersebut, diharapkan dapat menumbuhkan ekuitas merek pada pasar sasaran anak muda (baik laki-laki maupun perempuan) pada usia 18-25 tahun, bersekolah SMA atau kuliah, terdidik, akrab dengan teknologi, internet, dan budaya populer (generasi milenial), suka bergaul, memiliki banyak teman dan jaringan, suka berpetualang, dan tentunya mulai mengenal atau mulai menaruh perhatian pada seni tradisi, sekaligus merupakan pengguna langsung produk dan jasa Padepokan Asmorobangun.

\subsection{Perencanaan Media dan Kreatif, serta Konsep Tata Desain}

\subsubsection{Visualisasi Brand}

\section{a. Logo}

Secara mendasar, logo Padepokan Seni Topeng Asmorobangun yang telah dirancang merupakan stilisasi dari topeng tokoh utama Roman Panji, yakni Panji Asmorobangun, atau Inu Kertapati. Pertimbangan yang paling mendasar dari pemilihan tokoh ini dalam perwujudan logo yang pertama adalah kesesuaiannya dengan nama padepokan (Padepokan Seni Topeng Asmorobangun). Kedua, Panji Asmorobangun sebagai tokoh utama dalam repertoar Panji, sebagai representasi harapan Padepokan Seni Topeng Asmorobangun untuk menjadi yang paling utama, terbaik, mampu menjadi pengayom, serta selalu menjadi yang terdepan baik dalam konservasi maupun inovasi Wayang Topeng Malangan, khususnya di kota Malang.

Ketiga, dalam topeng Panji Asmorobangun, dari hubungan antar elemen didalamnya, menjelaskan tentang gambaran/citra ideal sosok pria Jawa yang memiliki tekad kuat, jujur, setia, dermawan, lapang dada (nrimo), berjiwa satria sekaligus seorang yang penyabar, dan mampu menjaga kehormatan dengan jalan menjauhkan diri dari perbuatan-perbuatan dosa. Nilai-nilai inilah yang kemudian digenggam dan diimplementasikan dalam segala aktivitas Padepokan Sani Topeng Asmorobangun. 


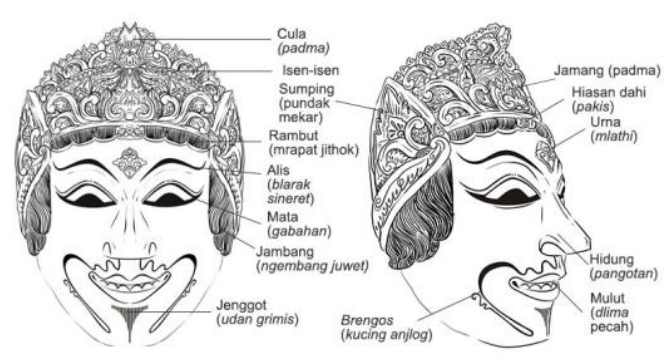

Gambar 4. Struktur topeng Panji Asmorobangun (Sumber: Melany \& Nirwana, 2015)

Topeng Panji Asmorobangun tersebut kemudian distilisasi dalam bentuk lineart artwork dan telah mengalami simplifikasi, namun tetap menitikberatkan pada kompleksitas visual. Bentuk stilisasi topeng tersebut menjadi picturemark logo, dengan penambahan lettermark "Asmorobangun" pada bagian bawah picturemark. Logo terdiri dari picturemark berupa: 1) ikon yang merupakan stilisasi topeng Panji Asmorobangun, serta lettermark 2) "Asmorobangun”, dan 3) "Padepokan Seni Topeng. Breakdown yang dilakukan terhadap topeng Panji Asmorobangun hingga menjadi ikon yang dipergunakan sebagai salah satu elemen dalam logo. Stilisasi dilakukan untuk menyeleksi elemen-elemen penting pada topeng dengan tujuan untuk menghasilkan bentuk yang lebih sederhana namun tetap memuat esensi penting topeng.

Dalam lettermark yang pertama dengan teks "Asmorobangun" dipergunakan typeface bergaya script "Echinos Park Script", diharapkan mampu menggambarkan keluwesan gerak tari, namun tetap dapat terbaca dengan mudah. Teks "Asmorobangun" dipenggal menjadi dua bagian "Asmoro" dan "Bangun" atas dasar pertimbangan komposisi, untuk mencapai keseimbangan dan kesatuan, namun tetap mempertimbangkan kaidah kebahasaan serta makna dasar kata tersebut.

Lettermark yang kedua dengan teks "Padepokan Seni Topeng" lebih kepada memperjelas atau menerangkan picturemark dan lettermark yang pertama. Lettermark yang kedua ini bersifat memberikan penjelasan mengenai entitas yang sedang direpresentasikan oleh logo, yakni sebuah Padepokan Seni Topeng. Dalam elemen ini, dipergunakan typeface bergaya Roman "Shonar Bangla", untuk memunculkan kesan "agung", serta "Klasik". Di samping dipergunakan pada lettermark utama logo, typeface "Echinos Park Script" juga dipergunakan pada tagline/slogan Padepokan Seni Topeng Asmorobangun, dengan teks "Menggenggam Warisan, Menjelajah Zaman". 

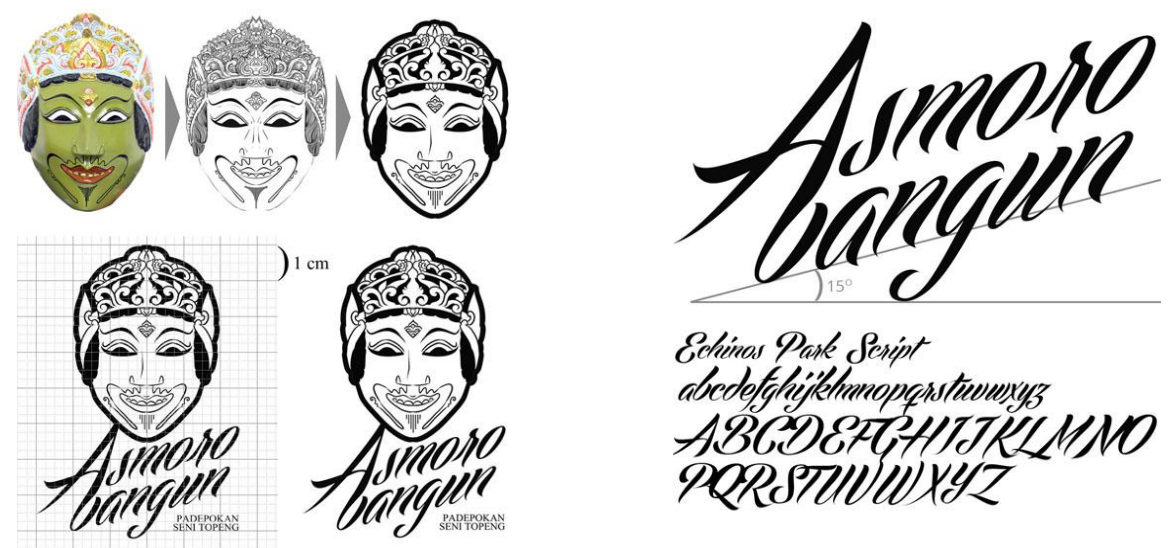

Echimas Paste Seript
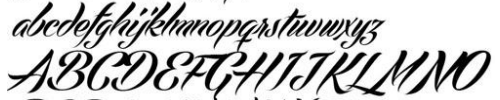

PRRSTUVIUYY

Gambar 5. Breakdown picturemark logo Padepokan Seni Topeng Asmorobangun (kiri) dan lettermark Padepokan Seno Topeng Asmorobangun typeface bergaya script "Echinos Park Script" (kanan). (Sumber: dokumentasi penulis)

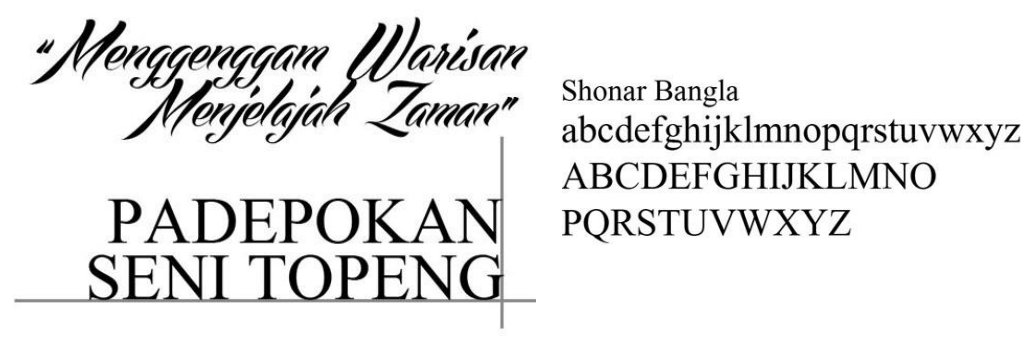

Gambar 6. Tagline/slogan Padepokan Seni Topeng Asmorobangun, dan lettermark logo yang kedua dengan typeface Shonar Bangla (typeface Shonar Bangla - kanan).

(Sumber: dokumentasi penulis)
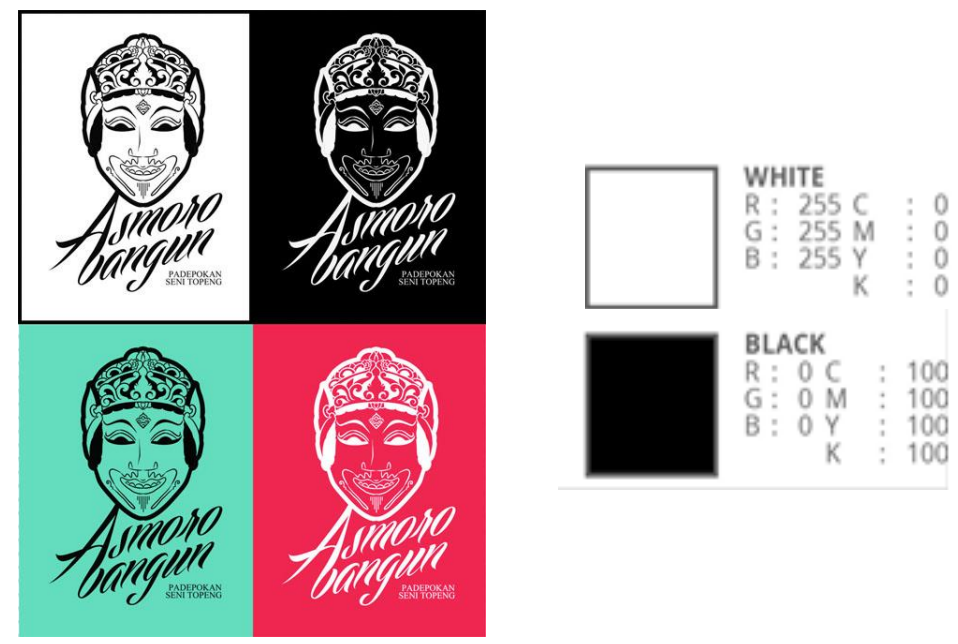

Gambar 7. Aplikasi dan aturan warna pada logo Padepokan Seni Topeng Asmorobangun.

(Sumber: dokumentasi penulis)

Pada dasarnya warna logo yang diperbolehkan adalah hitam dan putih, atau dalam bentuk warna positif dan negatif. Keputusan pemilihan diantara keduanya bergantung pada warna background medium, jika warna background cenderung gelap maka dipergunakan logo dengan 
bentuk warna positif (putih), jika background cenderung berwarna terang, maka dapat dipergunakan warna logo dalam bentuk negatif (hitam)

Freezone merupakan batas bersih atau area bebas logo. Freezone berfungsi agar logo dapat terbaca atau teridentifikasi secara optimal. Dalam ukuran point (pt), dimensi logo meliputi panjang sebesar $22 \mathrm{pt}$, dan tinggi sebesar $33 \mathrm{pt}$, maka batas bersih logo dibuat dengan ukuran standar 4 pt dari masing-masing sisi panjang dan tingginya. Freezone logo ini diterapkan pada semua bentuk aplikasi logo tanpa terkecuali. Baik pada media cetak maupun elektronik.

Ukuran $100 \%$ dari logo ini adalah ketika tinggi logo berukuran 9,6 cm (sudah termasuk freezone). Adapun ukuran minimal dari aplikasi logo ini adalah 25\%, untuk menjaga agar logo dapat memenuhi fungsinya sebagai identitas visual dengan optimal. Ukuran penggunaan logo disesuaikan dengan medium.

\section{b. Tipografi}

Jenis huruf yang dipergunakan dalam semua material Padepokan Seni Topeng Asmorobangun, baik media elektronik maupun print collateral adalah keluarga huruf Open Sans. Open Sans merupakan keluarga huruf dari jenis sans-serif yang memiliki clearity yang cukup tinggi, dan mengesankan modernitas.

\section{c. Warna Korporat}

Warna korporat merupakan beberapa warna yang secara baku (arbitrer) ditentukan untuk menjadi identitas suatu lembaga, institusi, dan entitas lain sejenis. Kecuali pada logo (harus hitam atau putih), warna korporat ini wajib diterapkan pada setiap bentuk komunikasi visual Padepokan Seni Topeng Asmorobangun. Cyan dan Magenta, merupakan warna aksentual dan penarik perhatian, oleh karena itu keduanya tidak dimaksudkan menjadi dominan untuk memunculkan efek emphasis.

\section{b. Fotografi}

Penggunaan fotografi dalam beragam media yang dirancang dimaksudkan sebagai sebuah bentuk ilustrasi dan juga salah satu elemen pembentuk nilai estetik intrinsik. Tidak ada batasan khusus terkait penggunaan foto sejauh tema yang disajikan masih berkaitan dengan Padepokan Seni Topeng Asmorobangun. Secara umum, foto yang dipergunakan terdiri dari foto hitam putih (grayscale) dan foto berwarna. Pada foto hitam putih, tonal warna dibuat lebih "warm" dengan warna kekuningan, sedangkan pada foto berwarna, intensitas warna cerah (kuning, hijau, merah, biru, atau warna-warna wayang topeng Malangan) lebih ditingkatkan, sehingga nampak lebih kontras. 


\section{c. Ilustrasi}

Secara mendasar ada dua pendekatan teknik perwujudan ilustrasi dalam beragam media komunikasi visual Padepokan Seni Topeng Asmorobangun, yakni dengan teknik fotografi dan digital drawing. Pada teknik fotografi dipegunakan foto hitam putih, sedangkan pada teknik digital drawing dipergunakan style lineart monochrome, tanpa fill warna.

\section{d. Elemen Lainnya}

Elemen visual pendukung sebagai unsur dekoratif dirancang dengan bentuk dasar lingkaran dengan harapan dapat lebih fleksibel ketika ditempatkan dalam sebuah bentuk komposisi visual. Secara ideal, elemen visual pendukung ini diimplementasikan sebagai background, bukan sebagai komposisi utama.

\subsubsection{Aplikasi Visualisasi Brand dalam Media Cetak dan Digital}

Elemen-elemen visual dalam brand yang telah dirancang tersebut, pada akhirnya diaplikasikan ke dalam beragam bentuk media komunikasi pemasaran. Media komunikasi pemasaran tersebut berupa: 1) Poster; 2) Roll Banner; 3) Stationery; 4) Iklan media sosial; dan 5) Kartu Nama. Poster dirancang dengan tujuan untuk mempublikasikan Gebyak Malem Senin Legi yang merupakan program unggulan dan strategis dari Padepokan Seni Topeng Asmorobangun. Poster ini memuat jadwal diselenggarakannya Gebyak Malem Senin Legi dalam kurun waktu satu tahun penuh (2017). Roll banner dirancang untuk diletakkan di padepokan, tidak jauh dari pendopo di mana Gebyak Malem Senin Legi diselenggarakan. Hal ini sekaligus memberikan informasi kepada pengunjung padepokan tentang program unggulan ini, baik yang hanya sekedar berkunjung ataupun melalukan pembelian. Stationery terdiri dari envelope, letterhead, dan ballpoint. Desain stationery ditujukan untuk surat menyurat yang nampak lebih profesional, semisal undangan, surat izin, surat pemberitahuan, dan lain sebagainya. Iklan media sosial dirancang dalam dimensi 500x500 px, sehingga berbentuk bujur sangkar, tujuannya untuk dipublikasikan di media sosial.
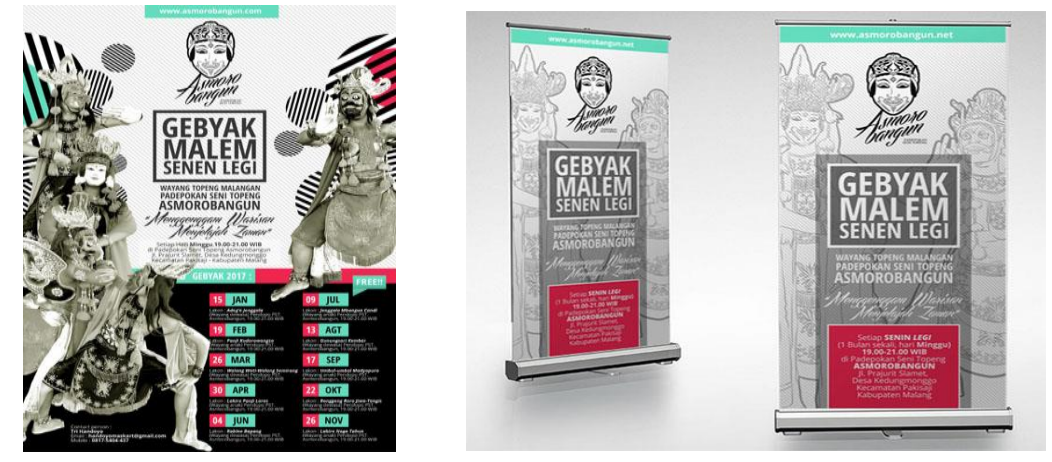

Gambar 8. Poster Padepokan Asmorobangun (kiri) dan Roll Banner Padepokan Asmorobangun (kanan). (Sumber: dokumentasi penulis) 

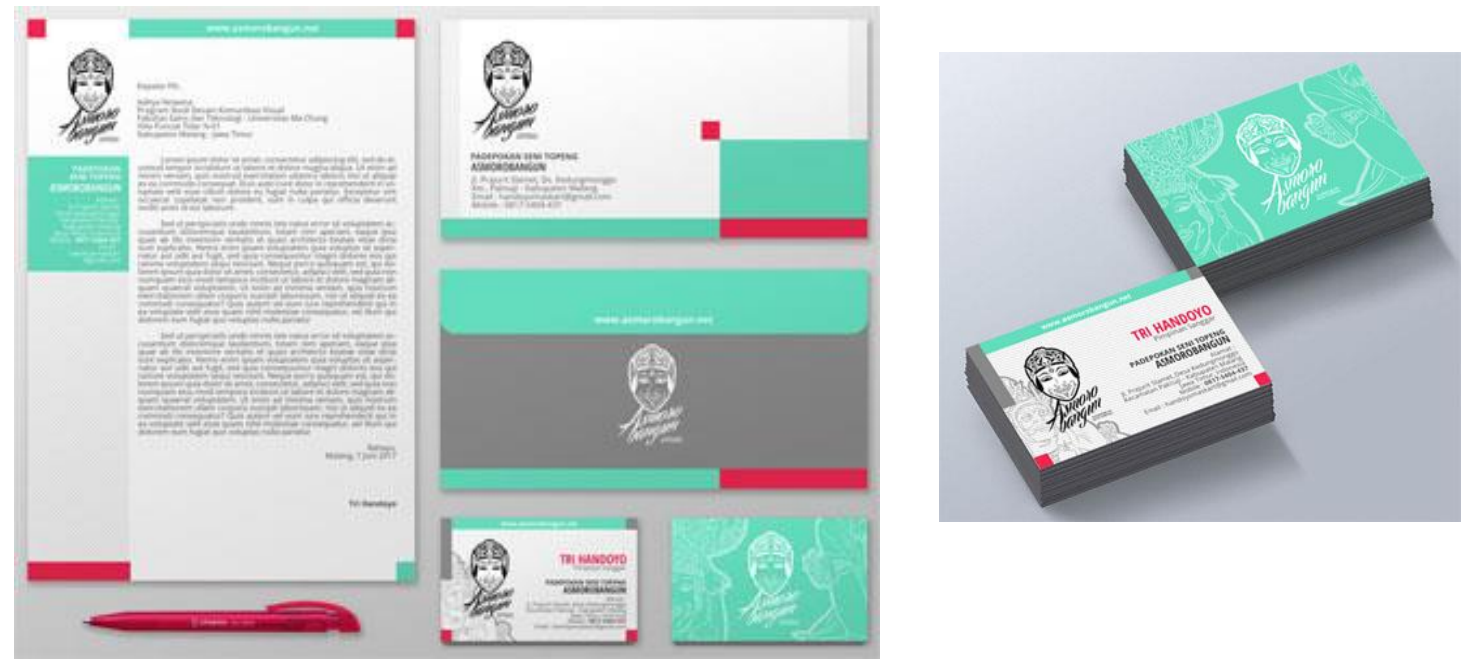

Gambar 9. Stationery (kiri) dan Kartu Nama (kanan).

(Sumber: dokumentasi penulis)
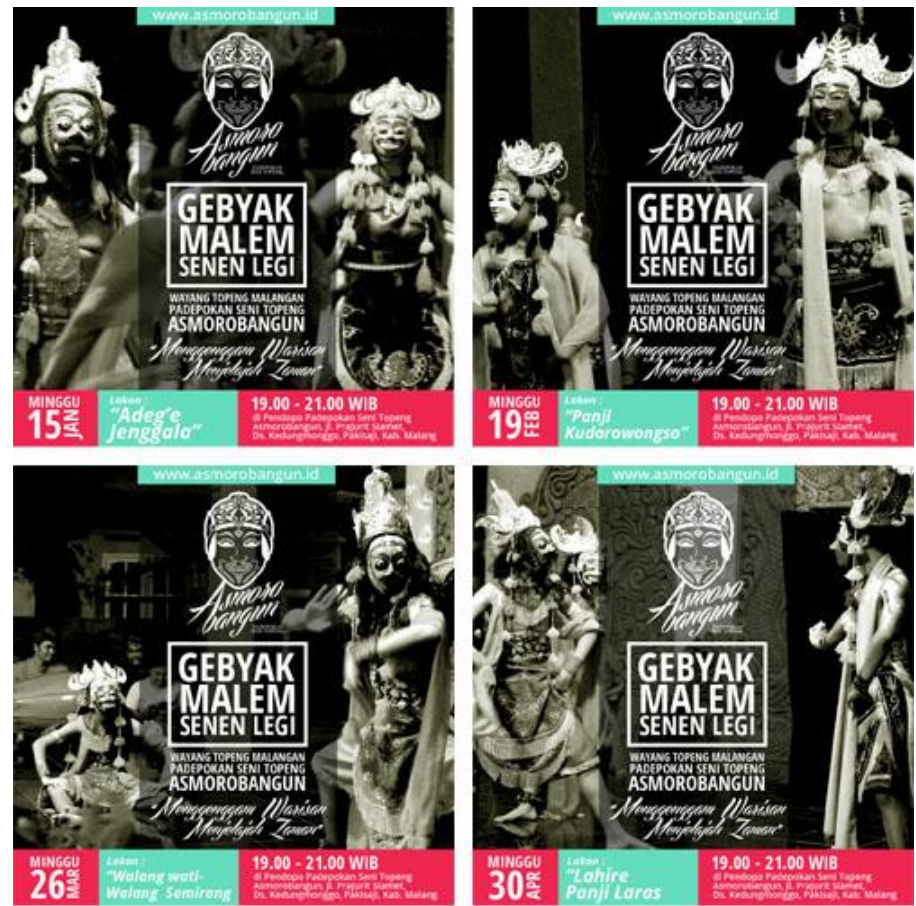

Gambar 10. Publikasi Media Sosial.

(Sumber: dokumentasi penulis)

\subsubsection{Publisitas}

Publisitas Padepokan Seni Topeng Asmorobangun dalam perancangan ini antara lain: 1) Corporate Identity System (CIS); 2) Website; dan 3) Buku Foto. Pada Corporate Identity System (CIS), konten berisi tentang petunjuk teknis brand dan implementasinya. Adapun website lebih sebagai profiling dan media komunikasi massa untuk menjangkau target pasar (dapat diakses di www.asmorobangun.com). 


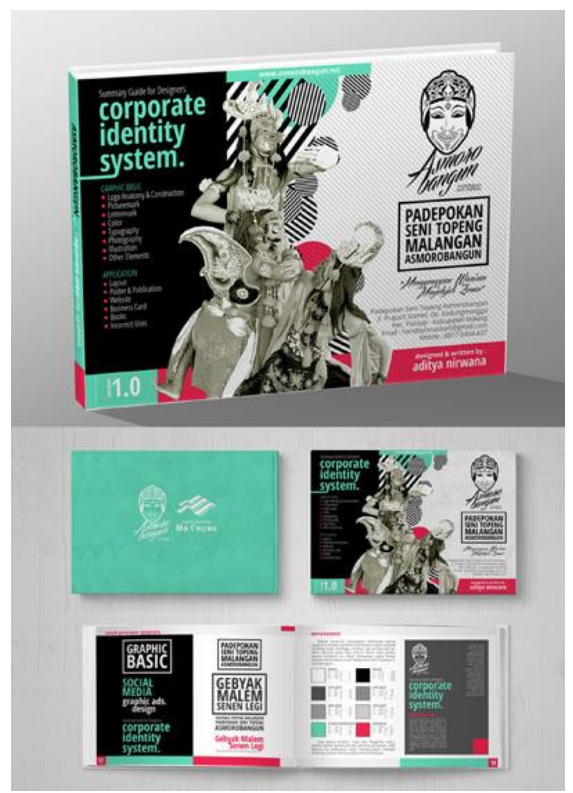

Gambar 11. Corporate Identity System (CIS). (Sumber: dokumentasi penulis)
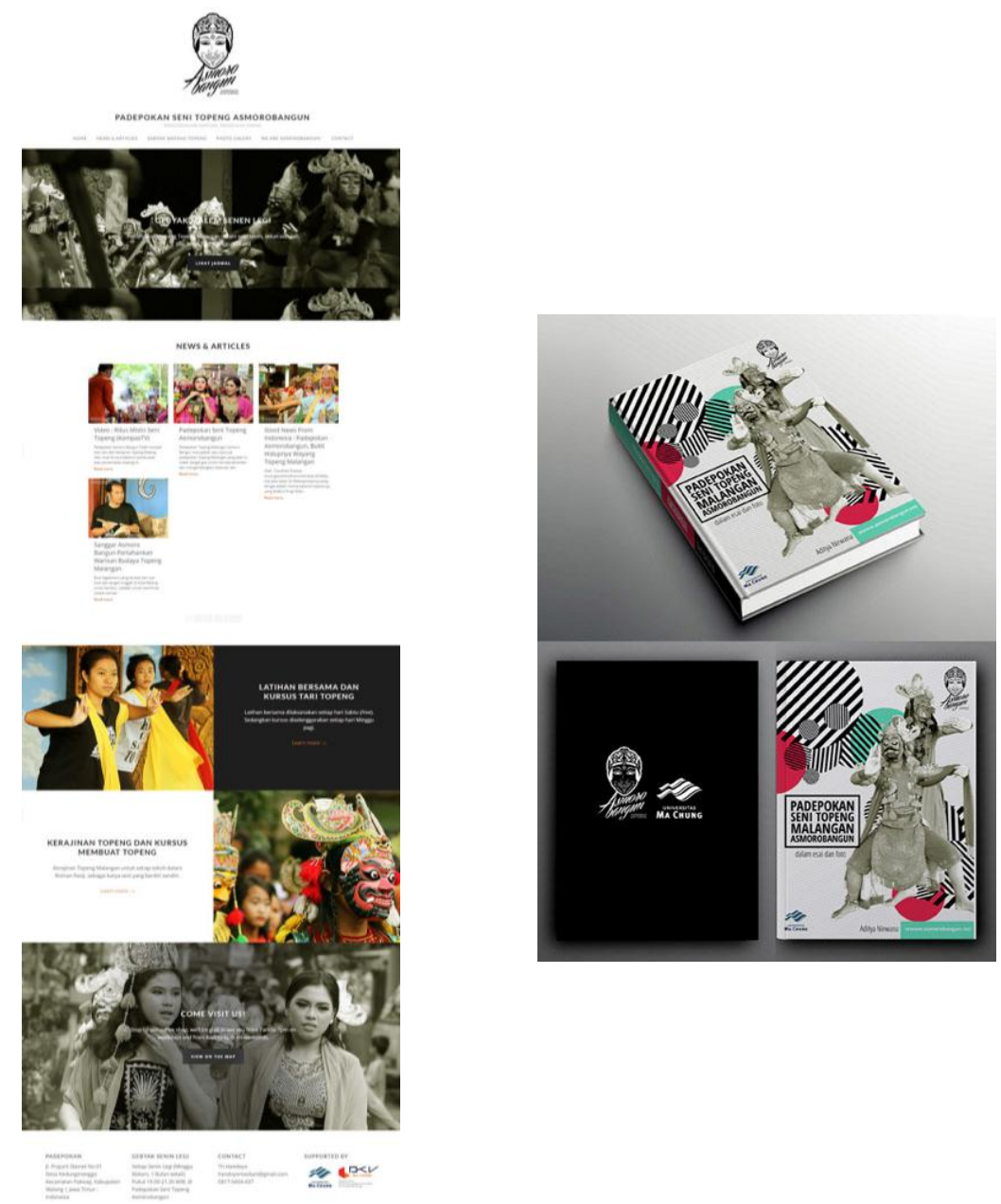

Gambar 12. Website www.asmorobangun.com (kiri) dan Photobook (kanan). (Sumber: dokumentasi penulis) 


\section{KESIMPULAN}

Berlandaskan hasil/kesimpulan dari analisis data, Customer-driven marketing strategy (STP), dan juga marketing mix (4P), maka didapat sebuah konsep perancangan yang merupakan jawaban dari rumusan masalah pertama, yakni merancang brand Padepokan Asmorobangun dalam bentuk atribut merek, berupa logo (lettermark, picturemark, typography, color), layout, ilustrasi, fotografi, poster, publikasi media sosial, bussiness card, dan juga stationery, yang seluruhnya terangkum dalam Corporate Identity System. Adapun dalam aspek publisitas, dirancang sebuah website dengan visualisasi yang konsisten serta atribut merk yang sudah dirancang. Website dirancang dengan tujuan untuk mendekatkan padepokan dengan segmen anak muda, yang oleh karena itu website dirancang dengan interface yang liquid (mobile friendly).

Visualisasi dari konsep tersebut, didapatkan identitas merek (brand) berupa logo, warna korporat, tipografi, fotografi, ilustrasi, dan elemen pendukung, yang kesemuanya itu terangkum dalam Corporate Identity System (CIS) sebagai petunjuk teknis komunikasi merek. Implementasi dari identitas merek tersebut, maka dirancang beberapa media komunikasi pemasaran berupa: 1) Poster; 2) Roll Banner; 3) Stationery; 4) Iklan media sosial; dan 5) Kartu Nama. Sedangkan pada aspek publisitas dirancang: 1) Corporate Identity System (CIS); 2) Website; dan 3) Photo Book. Melalui perancangan brand, media pemasaran, dan publisitas tersebut, diharapkan mampu meningkatkan ekuitas merek Padepokan Seni Topeng Asmorobangun, yang juga berfungsi sebagai media informasi bagi masyarakat kota Malang dalam memahami Wayang Topeng Malangan.

\section{DAFTAR PUSTAKA}

Hidajat, R., 2005. Struktur, Simbol, dan Makna Wayang Topeng Malang. Jurnal Bahasa dan Seni, 33(2). Hal: 270-282.

., 2014. Transformasi Nilai Lokal yang Diekspresikan Wayang Topeng Malang Sebagai Sumber Pendidikan Karakter. Jurnal Imaji, 12(2). Hal: 17-29.

Holt, C., 2000. Melacak Jejak Perkembangan Seni di Indonesia. Jakarta: Masyarakat Seni Pertunjukan Indonesia (MSPI).

Kotler, P., \& Armstrong, G., 2008. Principles of Marketing. New Jersey: Pearson Prentice Hall.

Kotler, P., \& Keller, K.L., 2007. Manajemen Pemasaran, Edisi 12, Jilid 1. Jakarta: Penerbit Erlangga. 
Melany., 2012. Eksistensi dan Strategi Pertahanan Tari dan Topeng Malangan di Malang Raya. Laporan Penelitian, Ma Chung Research Grant (MRG) 2012. Malang: Program Studi Sastra Inggris, Fakultas Bahasa dan Seni, Universitas Ma Chung.

Melany, \& Nirwana, A., 2015. Kajian Estetik Topeng Malangan (Studi Kasus di Padepokan Asmorobangun, Desa Kedungmonggo, Kecamatan Pakisaji, Kabupaten Malang). Jurnal Imaji, 13(2). 21-40

Moleong, L.J., 2014. Metodologi Penelitian Kualitatif, Edisi Revisi. Bandung: Remaja Rosdakarya

O’Guinn, T.C., Allen, T.C., \& Semenik, R.J., 2009. Advertising \& Integrated Brand Promotion. Mason: South Western Cengage Learning.

Sanyoto, S.E., 2006. Metode Perancangan Komunikasi Visual Periklanan. Yogyakarta: Dimensi Press.

Shimp, T.A., 2000. Periklanan Promosi, Aspek Tambahan Komunikasi Terpadu, Jilid 1. Jakarta: Penerbit Erlangga 